\title{
Littre Hernia - An Occasional Cause Of Acute Abdomen
}

\author{
Jurij Janež* \\ Department of Abdominal Surgery, University Medical Centre Ljubljana, Slovenia
}

Received: January 26, 2018; Published: February 05, 2018

*Corresponding author: Jurij Janež, Department of Abdominal Surgery, Universitiy Medical Centre Ljubljana, Slovenia, Email: jurij.janez@gmail.com

\section{Introduction}

Littre hernia is the protrusion of a Meckel diverticulum through a potential abdominal opening. It is named after a French physician and anatomist Alexis de Littre (July 17, 1654 - February 3, 1726), who reported an ileal diverticula and attributed them to traction [1]. Littre hernias are rare and develop more often in inguinal hernias than other types of abdominal wall hernias. Embryologically, Meckel diverticulum is the persistent intestinal part of the omphaloenteric duct through which the midgut communicates with the umbilical vesicle until the fifth week [2]. It occurs because the remnant of the omphalomesenteric canal, which should be closed by the 7 th, 8th week of gestation, does not close properly. The diverticulum can contain ectopic gastric, duodenal or pancreatic tissue and is the most common congenital anomaly of the gastrointestinal tract with estimates of prevalence ranging from $0.3 \%$ to $3 \%$. Generally, it remains asymptomatic and it is manifested by its complications, the most common of which are gastrointestinal bleeding, inflammation and obstruction [3].

In children the most common complication is gastrointestinal bleeding caused by ulceration due to the acid secretion by ectopic gastric mucosa. In adults, however, the most commonly observed complication is bowel obstruction followed by inflammation and bleeding It is found at the antimesenteric border of the ileum, usually located 30 to $90 \mathrm{~cm}$ from the ileocecal valve, measuring 3 to $6 \mathrm{~cm}$ in length and $2 \mathrm{~cm}$ in diameter [2]. The herniation of a Meckel diverticulum - the so-called Littre hernia - is extremely rare and less than 50 cases have been described in the literature over the past 300 years. Usual sites of Littre hernia are: inguinal (50\%), umbilical (20\%), and femoral (20\%). Meckel diverticulum may be accompanied in the sac by the ileal loop to which it is attached; rarely, it may undergo incarceration or strangulation, necrosis, and perforation $[4,5,6]$. Incarceration of a hernia is a term used to describe entrapment of the hernia contents leading to swelling of the trapped tissue.
This ultimately reduces arterial flow resulting in ischemia and necrosis of the hernia contents also termed strangulation. Such complicated groin hernias usually present with symptoms of bowel obstruction, skin changes or peritonitis and require emergency surgery, but in the extremely rare case of an incarcerated Littre hernia, the symptoms can be less severe and occur late in the course of the disease. This is because only the diverticulum and not the lumen of the intestine is involved, allowing the passage of feces [6]. Preoperative diagnosis of an incarcerated Littre hernia with abdominal ultrasound or computed tomography is extremely rare and it is normally an intraoperative finding. Routine resection of asymptomatic Meckel diverticulum is not advised. The gold standard treatment of a Littre hernia is a wedge resection of the Meckel diverticulum before the hernia repair [5]. In cases of perforation, care must be taken to not contaminate the hernia field [1].

\section{Conclusion}

The Littre hernia is a rare condition, but the surgeons must be aware of it. It is usually diagnosed intaroperatively. The standard treatment of Littre hernia is a wedge resection of the Meckel diverticulum and hernia repair.

\section{References}

1. Skandalakis PN, Zoras O, Skandalakis JE, Mirilas P (2006) Littre hernia: surgical anatomy, embryology, and technique of repair. Am Surg 72(3): 238-243.

2. Akin M, Kurukahvecioglu O, Tezcaner T, Anadol AZ, Onur K (2008) Acute hemiscrotum due to inguinoscrotal Littre hernia: a case report. Am J Emerg Med 26(8): 973.e3-4.

3. Kampourogloua G, Huyaga B, Pricaa S (2013) Incarcerated Femoral Littre's Hernia After Inguinal Hernia Repair, Report of a Case. Journal of Medical Cases 4(1): 1-3.

4. Aláez-Chillarón AB, Ramiro-Pérez C, Rodríguez-Velasco G, Calero-Amaro A, Latorre-Fragua $\mathrm{R}$, et al. Littré hernia: an unusual cause of intestinal obstruction. Cir Cir 80(2): 186-188. 
5. Citgez B, Yetkin G, Uludag M, Karakoc S, Akgun I, et al. (2011) Littre's hernia, an incarcerated ventral incisional hernia containing a strangulated meckel diverticulum: report of a case. Surg Today 41(4): 576-578.
6. Malling B, Karlsen AA, Hern J (2017) Littre Hernia: A Rare Case of an Incarcerated Meckel's Diverticulum. Ultrasound International Open 3(2):E91-E92.

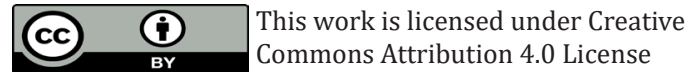

Submission Link: http://biomedres.us/submit-manuscript.php

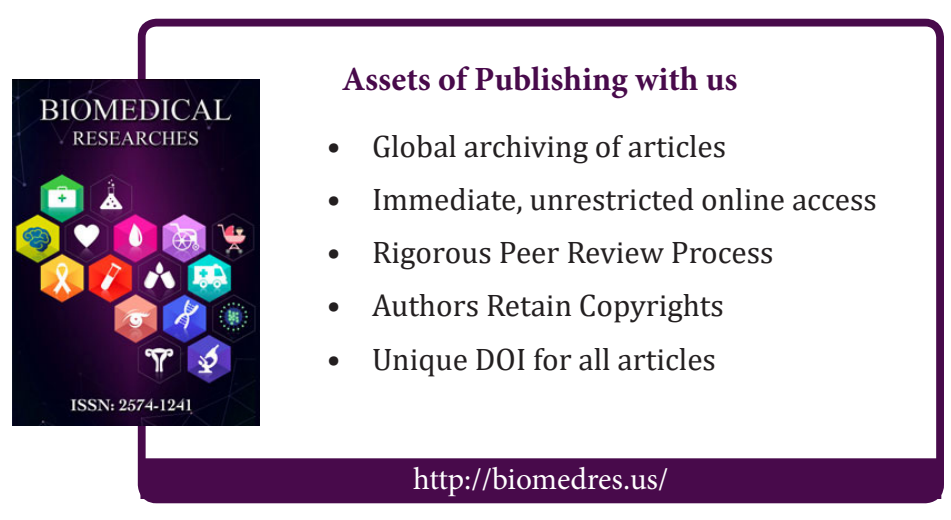

